Utah State University

DigitalCommons@USU

1972

\title{
Simulation of the daily growth of an Aspen population from the measured CO2-exchange rates of the components
}

\author{
G.C. Bate \\ D.T. Canvin
}

Follow this and additional works at: https://digitalcommons.usu.edu/aspen_bib

Part of the Forest Sciences Commons

\section{Recommended Citation}

Bate, G.C. and Canvin, D.T., "Simulation of the daily growth of an Aspen population from the measured C02-exchange rates of the components" (1972). Aspen Bibliography. Paper 5456.

https://digitalcommons.usu.edu/aspen_bib/5456

This Article is brought to you for free and open access by the Aspen Research at DigitalCommons@USU. It has been accepted for inclusion in Aspen Bibliography by an authorized administrator of DigitalCommons@USU. For more information, please contact

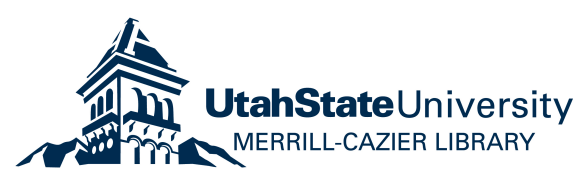




\author{
G. C. BATE ${ }^{2}$ AND D. T. CANVIN \\ Department of Biology, Queen's University, Kingston, Ontario \\ Received February 22, 1971
}

\begin{abstract}
Bate, G. C., and D. T. CANvin. 1972. Simulation of the daily growth of an aspen population from the measured $\mathrm{CO}_{2}$-exchainge rates of the components. Can. J. Bot. 50: 205-214.

The daily total $\mathrm{CO}_{2}$-exchange of an aspen population (32 trees) was measured using a growth chamber gas analysis system which had been shown to measure accurately the actual carbon gain of the population. The $\mathrm{CO}_{2}$-exchange rates of the components (e.g. roots, stems, leaves) were measured in the light and dark and these rates were used to calculate the total $\mathrm{CO}_{2}$-exchange of the population using a computer inodel. The carbon gain during the photoperiod was underestimated by $25 \%$ in the simulation while the carbon loss during the nyctoperiod was overestimated $100 \%$ by the simulation.
\end{abstract}

Bate, G. C., et D. T. CANvin. 1972. Simulation of the daily growth of an aspen population from the measured $\mathrm{CO}_{2}$-exchange rates of the components. Can. J. Bot. 50: 205-214.

L'échange quotidien tołal de $\mathrm{CO}_{2}$ d'une population de peupliers faux-trembles (32 arbres) a été mesuré en effectuant l'analyse des gaz dans une chambre de croissance, ce système s'étant avéré adéquat pour mesurer avec précision l'incorporation du carbone dans la population. Les taux d'échange des constituants (e.g. racines, tiges, feuilles) ont été mesurés à la lumière et à l'obscurité; les valeurs obtenues ont été utilisées pour calculer l'échange total du $\mathrm{CO}_{2}$ par la population à l'aide d'un modèle sur ordinateur. Dans la simulation, le gain en carbone a été sous-estimé de $25 \%$, alors que la perte en carbone pendant la nyctipériode a été surestimée de $100 \%$.

\section{Introduction}

The use of models to explain and predict growth and productivity has recently been the subject of a considerable amount of discussion (Setlik 1970), and different simulation models have been proposed to describe the growth process. Ledig (i969) proposed a model for tree seedlings based on rates of photosynthesis and on the distribution of photosynthate. Waggoner $(1969 a, b)$ related the physics of gas exchange, the biochemistry of growth, and the fluctuating environmental factors into a functional computer simulation. As total photosynthesis is the largest component that contributes to productivity, Duncan et al. (1967) developed a model describing the plant canopy and the rate of photosynthesis as related to the plant canopy and the light regime. DeWit and Brouwer (1968), and DeWit et al. (1970) have developed ELCROS, which is a model that attempts to describe the response of the plant on the basis of the complete plant growth system.

\footnotetext{
${ }^{1}$ Canadian IBP contribution No. 105.

2Present address: Department of Agriculture, University of Rhodesia, P.O. Box MP 167, Salisbury,
}

DeWit (1970) believes that the use of simulation will allow the integration in space and time of our knowledge regarding the principles and data of a system and will overcome some of the difficulties that are encountered when the application of this knowledge is attempted. At the same time he states his reservations as simulation "has still to prove itself" and where inadequate information is available "the model must therefore be verified by doing actual experiments with the model and the system on the explainable level." DeWit (1970) contends that it is naive to pursue construction of models that are supposed to simulate complex ecosystems like forests but instead one should construct more modest models while attempting to add to our knowledge of biological principles which form the base of model building. With a simple system it is, of course, easier to verify the principles and data that are used in the model and to estimate the magnitude cf the errors that are included in the calculations. Needless to say, it is not very likely that the errors of a more complex system will be less than those encountered in a simple system.

In a recent paper we have described a system that accurately measured, on a daily or monthly basis, the $\mathrm{CO}_{2}$-exchange between a population 
of plants and the atmosphere of a controlled envircnment cabinet (Bate and Canvin 1971a). The gas exchange rates of individual components within the population could be determined with a minimum of disturbance and the structure of the population could also be accurately determined. Since the above data could be obtained and since the total $\mathrm{CO}_{2}$ exchange was known, it seemed that such a system provided an ideal opportunity to test the accuracy of the "Model-building concept" on a population of plants.

\section{Materials and Methods}

\section{Gas Exchange of Population}

In a whole cabinet system as previously described (Bate and Canvin 1971a), a population of 32 aspen trees ( $\mathrm{Popu-}$ lus tremuloides $\mathrm{Michx}$ ) were grown from dormant 1 -yearold seedlings at a light intensity of $3.4 \times 10^{4} \mathrm{ergs.cm}-2$. $\mathrm{s}^{-1}(400-700 \mathrm{~m} \mu)$ immediately above the canopy; an 18-h photoperiod, $20 \mathrm{C}$ day and $14 \mathrm{C}$ night were used. After 48 days the $\mathrm{CO}_{2}$-exchange of the whole population was measured over a 24 -h period under the temperature conditions shown in Fig. 1. At 7.30 p.m., the temperature was altered manually to provide a change to be simulated in the model. The results of the 24-h $\mathrm{CO}_{2}$-exchange measurement were retained for comparison with the computer simulation.

The area of leaves was measured as described earlier (Bate and Canvin 1971a).

\section{Gas Exchange of Individual Leaves}

The system used to measure the $\mathrm{CO}_{2}$-exchange and transpiration rates of individual leaves in the light and dark is shown in Fig. 2. $\mathrm{CO}_{2}$ in air was supplied to the cuvette from calibrated tanks of gas (Bate et al. 1969). $\mathrm{CO}_{2}$-exchange was calculated as described earlier (Ludwig and Canvin 1971).
The air stream from the leaf chamber was passed through a coil to an electronic Hygrosensor (Hygrody. namics Inc., Silver Springs, Md.), both maintained at $27 \mathrm{C}$ in a constant temperature bath. The transpiration rate was calculated from the flow rate and the difference in the relative humidity of the air stream entering the leaf chamber and that of the air stream leaving the leaf chamber.

The flow rate through the leaf chamber was $500 \mathrm{ml}$. $\min ^{-1}$. Light intensity was measured with a YSI Kettering Model 65 radiometer and temperature was measured as previously described (Ludwig and Canvin 1971). Signals from the UNOR-2 and Hygrosensor were recorded on a Sargent Model DSRG potentiometric recorder.

\section{Gas Exchange of Single Plants}

The whole plant chamber (Fig. 3) was constructed in three sections from plexiglass. All joints were fabricated with an adhesive made from plexiglass chips dissolved in 1,2-dichloroethane and reinforced with $\frac{1}{8}$-in. screws tapped into the plexiglass (Bate 1970).

The gas exchange from three portions of a tree was measured concurrently and during measurements the connections through which the stem passed were sealed with a rubber stopper and Terostat (Type VII TerosonWerbe, GmbH Chemische Fabrik, Heidelberg, Germany).

The measurements of wood respiration were made with plants which had been stripped of all their foliage and replaced in the whole plant cuvettes.

The air in each section was circulated with a Redmond blower (Model AK41104, Electrosonic Industrial Sales Ltd., Toronto, Ont.) controlled by a variable transformer. A maximum photosynthetic rate of $8.2 \mathrm{mg} \mathrm{CO}_{2} \cdot \mathrm{dm}^{-2} \cdot \mathrm{h}^{-1}$ for an aspen tree canopy was achieved at air delivery rates from the blower of 275 liters. $\mathrm{min}^{-1}$ to 700 liters. $\mathrm{min}^{-1}$. When air circulation was increased to 1275 liters. $\mathrm{min}^{-1}$ the rate of photosynthesis decreased sharply to less than $1.5 \mathrm{mg} \mathrm{CO} 2 . \mathrm{dm}^{-2} \cdot \mathrm{h}^{-1}$.

Temperature control was achieved using the surrounding cabinet air and temperatures were measured using thermocouples (Bate and Canvin 1971a). Light intensity was measured as mentioned previously.

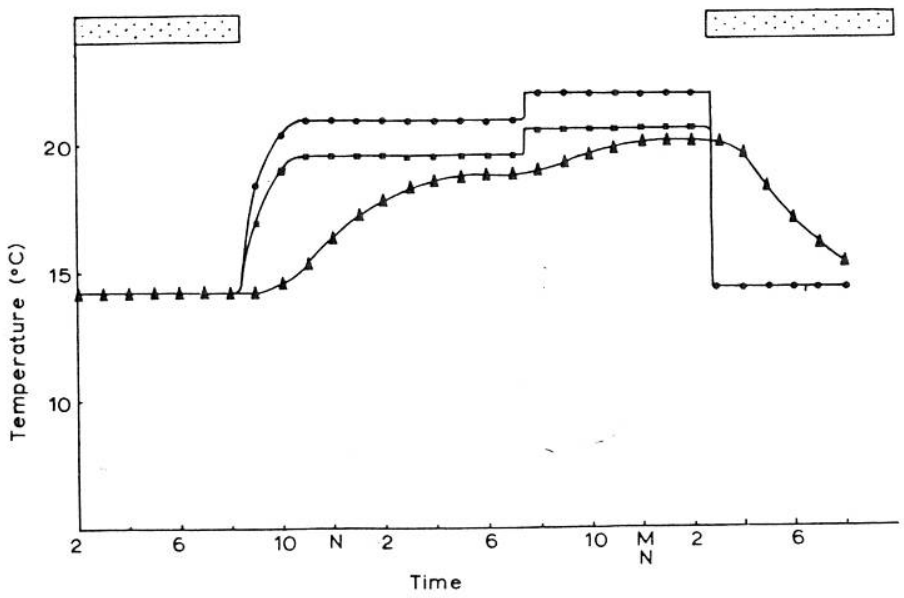

FIG. 1. Temperature of upper air ( $\bullet$ ), lower air ( lings grown for the purposes of computer simulation. Growth cabinet temperature settings at 20/14C day/ night. 
Air was drawn from the growth chamber into each of the sections of the plant chamber through $1-\mathrm{cm}$ holes in the side of the cuvette situated directly opposite the inlet ducts of the blowers. Air was drawn out of each section of the plant chamber with a pump (Type 406G, Reciprotor A/S, Copenhagen, Denmark) at a rate sufficient to give a $\mathrm{CO}_{2}$ differential between entering and exiting air of 10 to $30 \mathrm{ppm}$. The gas stream from each section of the plant chamber was then passed in turn through a condenser, a flowmeter, a cirier, a second flowmeter, and the sample side of an infrared gas analyzer (Model 215, Beckman). A portion of the air was allowed to exit from the gas stream after the first flowmeter. Air was pumped from a point near the inlet ports of the plant chamber via a con- denser, drier, and flowmeter to the reference cell of the infrared gas analyzer. The calculation of $\mathrm{CO}_{2}$-exchange was made as previously described (Ludwig and Canvin 1971). In most studies involving the three-section plant chamber the $\mathrm{CO}_{2}$-exchange measurements were made simultaneously with three infrared gas analyzers and the results were recorded and integrated (Bate and Canvin 1971a).

The transpiration rate of the plants was measured with the system described for the single leaf studies.

The plants were supplied with water and nutrient solution (Bate and Canvin 1971b) before the start of each measurement in the plant chamber. Where the measuring period exceeded 1 day the watering tube of the plant con-

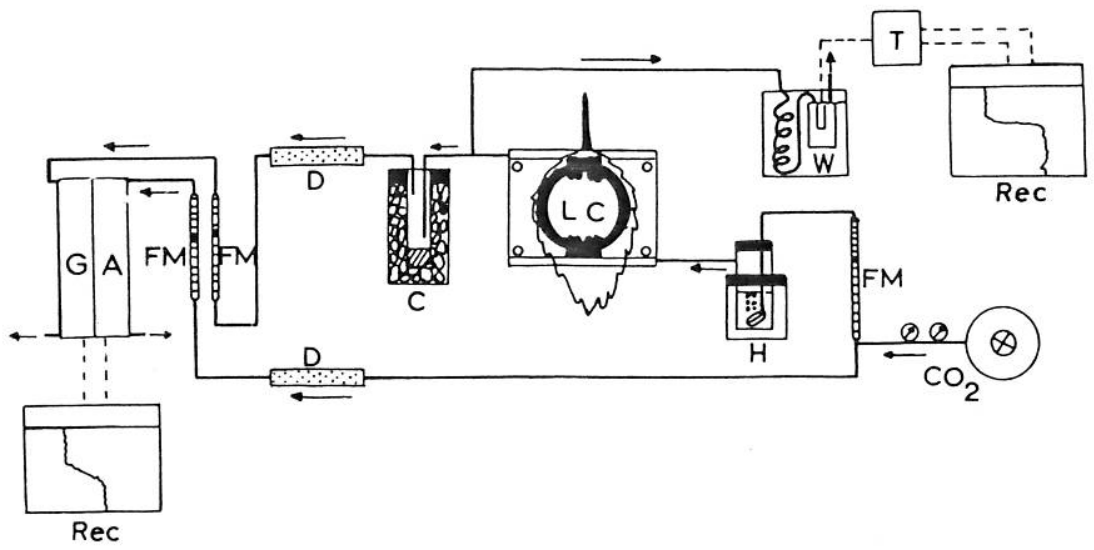

FIG. 2. System for measuring $\mathrm{CO}_{2}$-exchange and rate of transpiration of single leaves in the light and dark. Rec, recorder; G.A., infrared gas analyzer; FM, flowmeter; D, drying column; C, ice-bath condenser; $\mathrm{LC}$, leaf chamber; $\mathrm{H}$, temperature-controlled air humidifier; $\mathrm{CO}_{2}$, calibrated tank of $\mathrm{CO}_{2}$-in-air; $\mathrm{W}$, temperature-controlled hygrometer; $\mathrm{T}$, humidity transducer.

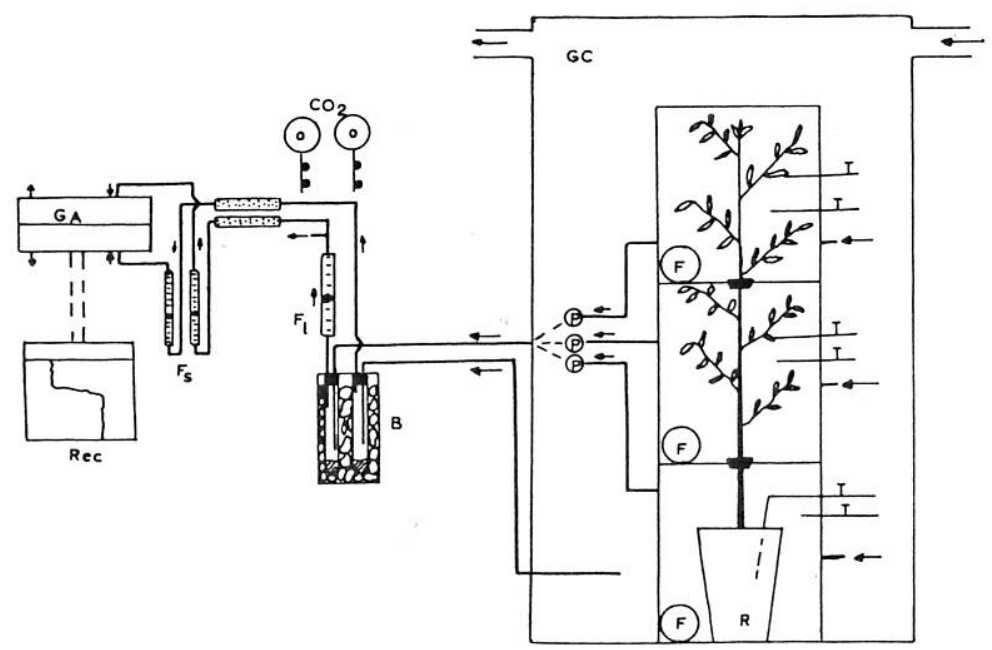

FIG. 3. System used to measure the $\mathrm{CO}_{2}$-exchange of different portions of a single whole plant. GA, 
tainer was connected to a remote watering device similar to that used for populations in the growth chamber (Bate and Canvin 1971b).

\section{Measurement of the Components of the Population}

From the population in the growth cabinet (see earlier), five trees were selected at random and, from each of them, five leaves in different positions were measured for their $\mathrm{CO}_{2}$-exchange rate in the light and dark using the individual leaf system.

Root and stem respiration was measured separately in three sections, as was the temperature dependency of dark respiration using the single-plant system.

The structure of the population was first determined from a sample of five trees but the structure was more accurately determined at the end of the experiment from all the trees in the population.

\section{Computer Simulator}

The computer program was written to calculate, from measurements on each of the population components, the total gas exchange of the population for a daily period. The program was written in Fortran IV and run on the WATFOR compiler of the IBM 360/50 computer. All values were expressed in $\mathrm{CO}_{2}$ equivalents.

The total population was subdivided into three major sections:

$S_{1}$, that portion of the population above $1.0 \mathrm{~m}$ from the floor of the growth cabinets;

$S_{2}$, total between 0.4 and $1.0 \mathrm{~m}$; and

$S_{3}$, roots and stem below $0.4 \mathrm{~m}$.

Each of these major sections was further subdivided as follows:

$$
\begin{aligned}
& S_{1}=S_{1 \mathrm{~L}}+S_{1 \mathrm{~W}} \\
& S_{2}=S_{2 \mathrm{~L}}+S_{2 \mathrm{~W}} \\
& S_{3}=S_{3 \mathrm{~W}}+S_{3 \mathrm{R}}
\end{aligned}
$$

where $\mathrm{L}=$ leaf component, $\mathrm{W}=$ wood (stem, bark, and branch) component, and $\mathrm{R}=$ root component.

The conservation of $\mathrm{CO}_{2}$ in three parts was subdivided into a component for photoperiod and a component for nyctoperiod. Hence, the basic conservation program was written as follows for the photoperiod.

Component
$\begin{gathered}\mathrm{d} S_{1} / \mathrm{d} t \\ \mathrm{~d} S_{2} / \mathrm{d} t \\ \mathrm{~d} S_{3} / \mathrm{d} t\end{gathered}$

$$
\begin{gathered}
\text { Photoperiod } \\
=P_{1} \alpha S_{1}-q_{1 \mathrm{w}}(1-\alpha) S_{1} \\
=P_{2} \beta S_{2}-q_{2 \mathrm{w}}(1-\beta) S_{2} \\
=-q_{3 \mathrm{R}}\left(S_{1}+S_{2}+z S_{3}\right)-q_{3 \mathrm{w}} z S_{3}
\end{gathered}
$$

where $P_{1}$ is the rate of apparent photosynthesis of $S_{1}$ ( $\left.\mathrm{mg} \mathrm{CO} \mathrm{CO}_{2} \cdot \mathrm{dm}^{-2} \cdot \mathrm{h}^{-1}\right), \alpha$ is the proportion of $S_{1}$ that is photosynthetic (weight/weight), $q_{1 \mathrm{w}}$ is the rate of wood respiration in $S_{1}, P_{2}$ is the rate of apparent photosynthesis of $S_{2}, \beta$ is the proportion of $S_{2}$ that is photosynthetic, $q_{2 \mathrm{~W}}$ is the rate of respiration of wood in $S_{2}, q_{3 \mathrm{R}}$ is the rate of root respiration, $q_{3 \mathrm{~W}}$ is the rate of respiration of wood in $S_{3}$ and $z$ is the proportion of wood in $S_{3}$. The values $q_{1 \mathrm{w}}, q_{2 \mathrm{w}}, q_{3 \mathrm{w}}$, and $q_{3 \mathrm{R}}$ were temperature dependent and since temperature $(t)$ was time dependent, each of the foregoing coefficients was time dependent.

In both the photoperiod and the nyctoperiod, the coefficient of root respiration was expressed in terms of total top dry weight. This was used because the coefficient of variation of root respiration based on this parameter was low and was more practical than the coefficient of respiration per unit of total dry weight of roots, which was more difficult to measure accurately.

Root respiration was measured on the intact plant root systems of seven trees by using the bottom section of the whole plant chamber. The average rate of root respiration $\left(q_{3 \mathrm{R}}\right)$ was $1.27 \pm 0.16$ (S.E.) $\mathrm{mg} \mathrm{CO} 2 \cdot \mathrm{g}^{-1}$ $\left(S_{1}+S_{2}+S_{3 \mathrm{w}}\right) \cdot \mathrm{h}^{-1}$ at $20 \mathrm{C}$. The effect of temperature $(T)$ on root respiration was determined on the seven trees over the temperature range 15 to $25 \mathrm{C}$; the average $\mathrm{d} q_{3 \mathrm{R}} / \mathrm{d} T$ was equal to $0.06 \mathrm{mg} \mathrm{CO} \mathrm{CO}_{2} \cdot \mathrm{g}^{-1}\left(S_{1}+S_{2}+S_{3 \pi}\right)$. $\mathrm{C}^{-1}$.

Temperature was shown to be a step-function of time (Fig. 1) and the trapezoidal rule was used to solve the equations over the specified time period.

In the simulation, $\Delta t=1 \mathrm{~min}$ but, except where abrupt changes occurred, the temperature changes were made over 1-h intervals assuming a linear rate of change over the 1 -h period.

The equations solved for the nyctoperiod were

$$
\begin{aligned}
& \mathrm{d} S_{1} / \mathrm{d} t=-\left[q_{1 \mathrm{~L}} \alpha S_{1}+(1-\alpha) q_{1 \mathrm{~W}} S_{1}\right] \\
& \mathrm{d} S_{2} / \mathrm{d} t=-\left[q_{2 \mathrm{~L}} \beta S_{2}+(1-\beta) q_{2 \mathrm{~W}} S_{2}\right] \\
& \mathrm{d} S_{3} / \mathrm{d} t=-\left[q_{3 \mathrm{R}}\left(S_{1}+S_{2}+z S_{3}\right)-q_{3 \mathrm{w}} z S_{3}\right]
\end{aligned}
$$

where $q_{1 \mathrm{~L}}$ and $q_{2 \mathrm{~L}}$ are the respiration rates of the leaves.

\section{Results}

The rate of photosynthesis $\left(P_{1 \mathrm{~L}}\right.$ and $\left.P_{2 \mathrm{~L}}\right)$ used in the simulation was $7.6 \pm 0.6$ (S.E.) $\mathrm{mg}$ $\mathrm{CO}_{2} \cdot \mathrm{dm}^{-2} \cdot \mathrm{h}^{-1}$ at $20 \mathrm{C}$. This value was determined by attaching the individual leaf chamber to each of 25 leaves in the identical position in which they were located in the canopy. The average rate of leaf respiration $\left(q_{1 \mathrm{~L}}\right.$ and $\left.q_{2 \mathrm{~L}}\right)$ was $1.5 \pm 0.09$ (S.E.) $\mathrm{mg} \mathrm{CO}_{2} \cdot \mathrm{dm}^{-2} \cdot \mathrm{h}^{-1}$ at $15 \mathrm{C}$. The value of dark respiration was measured on the same 25 leaves as photosynthesis but during the natural dark period (i.e. the 6-h nyctoperiod). For purposes of the program, the temperature $(T)$ dependency of $P_{1 \mathrm{~L}}$ and $P_{2 \mathrm{~L}}$ was ignored but that for $\mathrm{d} q_{1 \mathrm{~L}} / \mathrm{d} T$ and $\mathrm{d} q_{2 \mathrm{~L}} / \mathrm{d} T$ was $0.15 \mathrm{mg} \mathrm{CO}_{2} \cdot \mathrm{dm}^{-2} \cdot \mathrm{C}^{-1}$. The temperature dependency $(T)$ of $P_{1 \mathrm{~L}}$ and $P_{2 \mathrm{~L}}$ was ignored because in the experiment the temperature range of $19.25-20.5 \mathrm{C}$ was used. This had previously caused no response at the light intensity used (Bate 1970). At different temperatures, a temperature dependency would have to be incorporated.

Before the leaf measurements on the above population, a considerable number of determinations were made on individual leaves from similar aspen populations to determine if specific leaf characteristics influenced the gas exchange. If it could be established which factors 
were related to high or low rates of $\mathrm{CO}_{2}-$ exchange, a reduction of error might be possible by specifically sampling with these factors in mind and incorporating the relationship into the model. No correlation was found between the rates of photosynthesis or respiration and the chlorophyll content of the leaves, leaf thickness, specific leaf area, dry matter content, or total area of an individual leaf (Bate 1970). A decreased rate of photosynthesis was observed with decreased light intensity with both individual leaves (Bate 1970) and aspen populations (Bate and Canvitı 1971b), and it was anticipated that the photosynthetic response of the leaves to light intensity and the light intensity regime in the canopy would need to be incorporated into the model. When the measurements were performed on the 25 sample leaves, however, no correlation could be found between the photosynthetic rate and either the distance of the leaves from the light canopy or the light intensity vertically incident on the leaves (Bate 1970). This was unexpected and surprising since light intensity is included in all models and has been dealt with extensively by Duncan et al. (1967). It is possible that our unidirectional light intensity measurements did not adequately describe the light regime surrounding each leaf and that a better estimation could be obtained from a light measuring device that integrates over a complete sphere. It should also be noted, however, that light intensity is not the only factor that influences the rate of photosynthesis of an individual leaf as age of leaf is also an important factor. Under constant light $(2.1 \times$ $10^{4}$ ergs. $\left.\mathrm{cm}^{-2} . \mathrm{s}^{-1}, 400-700 \mathrm{~m} \mu\right)$ and temperature (21C) the highest photosynthetic rates were observed with midcanopy leaves. Lower rates were observed with the top-canopy (young) leaves and the bottom canopy (old) leaves (Bate 1970). Since no specific correlations existed between leaf characteristics or light intensity, the 25-leaf sample included a vertical sampling through the canopy and the average photosynthetic and respiration rates thus included an averaging factor for light intensity and leaf position on the plant.

From the extensive single leaf measurements that were made before sampling in the aspen population, the relationship between rates of
Other workers (Ludwig et al. 1965; McCree 1970) have shown that the rate of dark respiration was related to the rate of photosynthesis when photosynthesis was altered with light intensity. No correlation between rate of photosynthesis and rate of dark respiration (measured during the normal nyctoperiod) could be found, however (Fig. 4), and both rates were determined for all leaves sampled in the population.

The rate of wood respiration was determined on trees immediately after defoliation, using the whole plant chamber. The respiration rate of the upper wood $\left(q_{1 \mathrm{w}}\right)$ was $2.6 \pm 0.4$ (S.E.) $\mathrm{mg}$ $\mathrm{CO}_{2} \cdot \mathrm{g}^{-1}$ (dry weight, wood) $\mathrm{h}^{-1}$ at $20 \mathrm{C}$, which was higher than that of the lower more mature

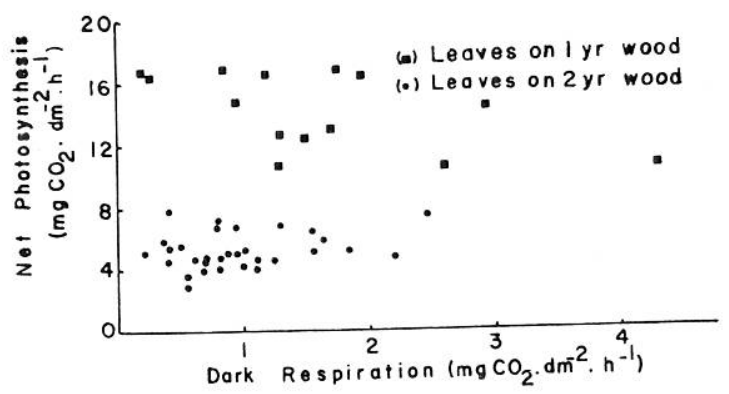

FIG. 4. Relationship between the rate of net photosynthesis $\left(3.8 \times 10^{4}\right.$ ergs.cm $\left.{ }^{-2} . \mathrm{s}^{-1}(400-700 \mathrm{m \mu}), 20 \mathrm{C}\right)$ and dark respiration $(20 \mathrm{C})$ of aspen leaves on 1-year-old wood (a) and the relationship between net photosynthesis $\left(2.95 \times 10^{4}\right.$ ergs.cm $\left.{ }^{-2} . \mathrm{s}^{-1}(400-700 \mathrm{m \mu}), 20 \mathrm{C}\right)$ and dark respiration $(20 \mathrm{C})$ of aspen leaves on 2-year-old wood ( ).

TABLE 1

Structure of the aspen population used in the computer simulator and the estimates of the proportions and total based on sample tree measurements

\begin{tabular}{|c|c|c|c|c|}
\hline \multirow[b]{2}{*}{ Component } & \multicolumn{2}{|c|}{ From sample trees } & \multicolumn{2}{|c|}{ Whole population } \\
\hline & $\begin{array}{c}\text { Dry } \\
\text { wt., }{ }^{*} \mathrm{~g}\end{array}$ & $\begin{array}{l}\text { Propor- } \\
\text { tion, } \%\end{array}$ & $\begin{array}{c}\text { Dry } \\
\text { wt., }{ }^{*} \mathrm{~g}\end{array}$ & $\begin{array}{l}\text { Propor- } \\
\text { tion, } \%\end{array}$ \\
\hline \multicolumn{5}{|l|}{$\begin{array}{l}\text { Upper canopy } \\
\left(S_{1}\right)\end{array}$} \\
\hline Leaves & 146.9 & 10.0 & 94.5 & 10.5 \\
\hline Wood & 63.0 & 4.3 & 51.8 & 5.8 \\
\hline \multicolumn{5}{|l|}{$\begin{array}{c}\text { Midcanopy } \\
\left(S_{2}\right)\end{array}$} \\
\hline Leaves & 193.0 & 13.2 & 86.5 & 9.6 \\
\hline Wood & 249.9 & 17.0 & 174.5 & 19.5 \\
\hline \multicolumn{5}{|l|}{$\begin{array}{l}\text { Lower portion } \\
\qquad\left(S_{3}\right)\end{array}$} \\
\hline Roots & 679.0 & 46.3 & 386.0 & 43.1 \\
\hline Wood & 135.0 & 9.2 & 102.7 & 11.5 \\
\hline
\end{tabular}


wood $\left(q_{2 \mathrm{w}}\right)\left(0.7 \pm 0.1\right.$ (S.E.) $\mathrm{mg} \mathrm{CO}_{2} \cdot \mathrm{g}^{-1}$ (dry weight, wood) $\mathrm{h}^{-1}$ at $18.5 \mathrm{C}$ ). In the model, the rate of respiration of $q_{3 \mathrm{w}}$ was assumed to be similar to the respiration rate of $q_{2 \mathrm{w}}$. The temperature dependency of $q_{1 \mathrm{w}}$ was measured: $\left(\mathrm{d} q_{1 \mathrm{w}} / \mathrm{d} T\right)=0.13 \mathrm{mg} \mathrm{CO}_{2} \cdot \mathrm{g}^{-1}$ (dry weight, wood) $\mathrm{C}^{-1}$. The values for $q_{2 \mathrm{w}}$ and $q_{3 \mathrm{w}}$ were not measured and a $\mathrm{Q}_{10}$ of $2,\left(\mathrm{~d} q_{2 \mathrm{w}} / \mathrm{d} T\right)=\left(\mathrm{d} q_{3 \mathrm{w}} /\right.$ $\mathrm{d} T)=0.06 \mathrm{mg} \mathrm{CO}_{2} \cdot \mathrm{g}^{-1}$ (dry weight, wood) $\mathrm{C}^{-1}$ was assumed.

The rate of root respiration was expressed on the basis of dry weight of whole plant, dry weight of roots, area of leaves, dry weight of stems and branches, and dry weight of total shoot (Bate 1970). The lowest coefficient of variation $(11.5 \%)$ was obtained on the basis of dry weight of stems and branches but, since the coefficient of variation was not much larger $(12.6 \%)$ and the data were easier to obtain, the rate was expressed on the basis of dry weight of total shoot.

The structure of the aspen population was determined from five sample trees and at the end of the experiment from the total population (Table 1). The percentage distribution of weight in the various components was reasonably well determined from the sample but the total weight in each fraction was considerably overestimated. To avoid introduction of additional errors in the computer simulation, the structure that was determined from the whole population was used initially in the calculations.

The first program produced a $\mathrm{CO}_{2}$-exchange pattern for the population that underestimated the carbon gain during the first part of the day and which overestimated the respiration rate of the population during the night (Fig. 5). The decrease in the initial high rate of photosynthesis was followed and this suggested that this decrease was due in large part to increased root respiration as a result of increasing temperatures (Fig. 1). The increased respiration rate at the beginning of the second night and the fall of respiration during the dark period was also reproduced, again suggesting that this resulted from the temperature changes occurring in the rooting medium (Fig. 1). The decrease in rate of carbon gain during the latter part of the day was not simulated and further consideration was given to this aspect.

The first program assumed that the leaves gained weight during the day while all the other components lost weight. This was clearly impossible and the program was reairanged as follows:

$$
\begin{aligned}
\mathrm{d} S_{1} / \mathrm{d} t=M_{1}(\mathrm{~d} S / \mathrm{d} t) ; \mathrm{d} S_{2} / \mathrm{d} t & = \\
M_{2}(\mathrm{~d} S / \mathrm{d} t) & \text { and } \mathrm{d} S_{3} / \mathrm{d} t=M_{3}(\mathrm{~d} S / \mathrm{d} t)
\end{aligned}
$$

where $\mathrm{d} S / \mathrm{d} t=\left[\begin{array}{llll}P & \alpha & S_{1}-q_{1 \mathrm{w}}(1-\alpha) & S_{1}\end{array}\right]+$ $\left[\begin{array}{llll}P & \beta & S_{2}-q_{2 \mathrm{w}}(1-\beta) & S_{2}\end{array}\right]+\left[\begin{array}{ll}-q_{3 \mathrm{R}} & \left(S_{1}+\right.\end{array}\right.$

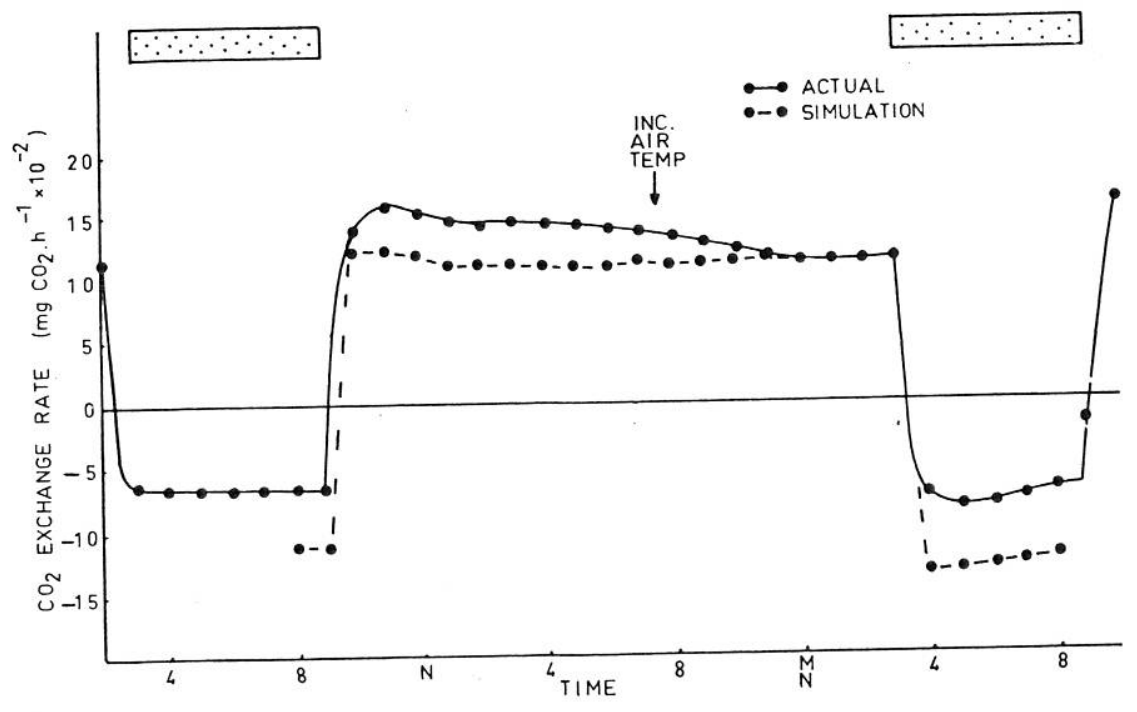

Fig. 5. Comparison of measured net assimilation rate for a population of aspen seedlings and a computer simulated model. Carbon gain not distributed, no fall of photosynthetic rate. Shaded areas indicate nyctoperiod. 
TABLE 2

The distribution of dry weight gain among the components of an aspen population ( 40 trees) after 85 days of growth. Light intensity, $4.85 \times 10^{4}$ ergs.cm ${ }^{-2} . \mathrm{s}^{-1}$; photoperiod, $18 \mathrm{~h}$; day/night temperatures, 20/15C

\begin{tabular}{lcccc}
\hline \hline & $\begin{array}{c}\text { Initial } \\
\text { dry } \\
\text { wt., g }\end{array}$ & $\begin{array}{c}\text { Final } \\
\text { dry } \\
\text { wt., g }\end{array}$ & $\begin{array}{c}\text { Dry } \\
\text { wt. } \\
\text { gain, g }\end{array}$ & $\begin{array}{c}\% \text { of } \\
\text { total } \\
\text { gain } \\
\text { retained }\end{array}$ \\
\hline Leaves & 280 & 611 & 331 & 54 \\
Stem, branches & 486 & 695 & 209 & 34 \\
Roots & 310 & 380 & 70 & 12 \\
Total & 1076 & 1686 & 610 & 100 \\
\hline
\end{tabular}

$\left.\left.S_{2}+z S_{3}\right)-q_{3 \mathrm{w}} z S_{3}\right]$ and $M_{1}, M_{2}$, and $M_{3}$ are the proportional amounts of the total net gain $\mathrm{d} S / \mathrm{d} t$ retained respectively in $S_{1}, S_{2}$, and $S_{3}$.

The distribution of newly gained carbon was ascertained from a population of 40 aspen trees (Bate 1970) which had been sampled in leaf and which had been grown for a further 85 days in the growth chamber. Of the total dry weight gain $54 \%$ of $\mathrm{d} S / \mathrm{d} t$ was retained by the leaves, $34 \%$ of $\mathrm{d} S / \mathrm{d} t$ was retained by the stem, and $12 \%$ of $\mathrm{d} S / \mathrm{d} t$ was retained by the roots (Table 2). The distribution of dry weight gain to each of the components was made in proportion to the weight distribution of that component within $S_{1}, S_{2}$, or $S_{3}$.
$M_{1}, M_{2}$, and $M_{3}$ were $0.34,0.44$, and 0.22 respectively and carbon redistribution was performed after each 1-min interval. The result from the simulation program was very similar to that shown in Fig. 5 and showed that the decrease in carbon gain during the latter part of the day was not due to the redistribution of carbon.

To simulate the observed daily decrease in photosynthesis the values of $P_{1 \mathrm{~L}}$ and $P_{2 \mathrm{~L}}$ were decreased over the last $11 \mathrm{~h}$ of the photoperiod at the rate of $0.17 \mathrm{mg} \mathrm{CO} 2 \cdot \mathrm{dm}^{-2} \cdot \mathrm{h}^{-1} \cdot \mathrm{h}^{-1}$. The time at which the decrease started and the average rate of decrease was based on the averages determined on four trees in the whole plant chamber.

The decrease in rate of $\mathrm{CO}_{2}$ gain that was observed with this population (Fig. 5) had been observed with many previous populations (Bate and Canvin 1971a, 1971b) and it was investigated more closely with the whole plant chamber. A typical result is shown in Fig. 6 and it can be seen that the photosynthetic rate of the canopy decreased about $10 \%$ during the last $6 \mathrm{~h}$ of the photoperiod. The transpiration rate actually increased during that time indicating that the result was not due to stomatal closure, a finding consistent with our earlier arguments (Bate and Canvin 1971a, 1971b). The increased

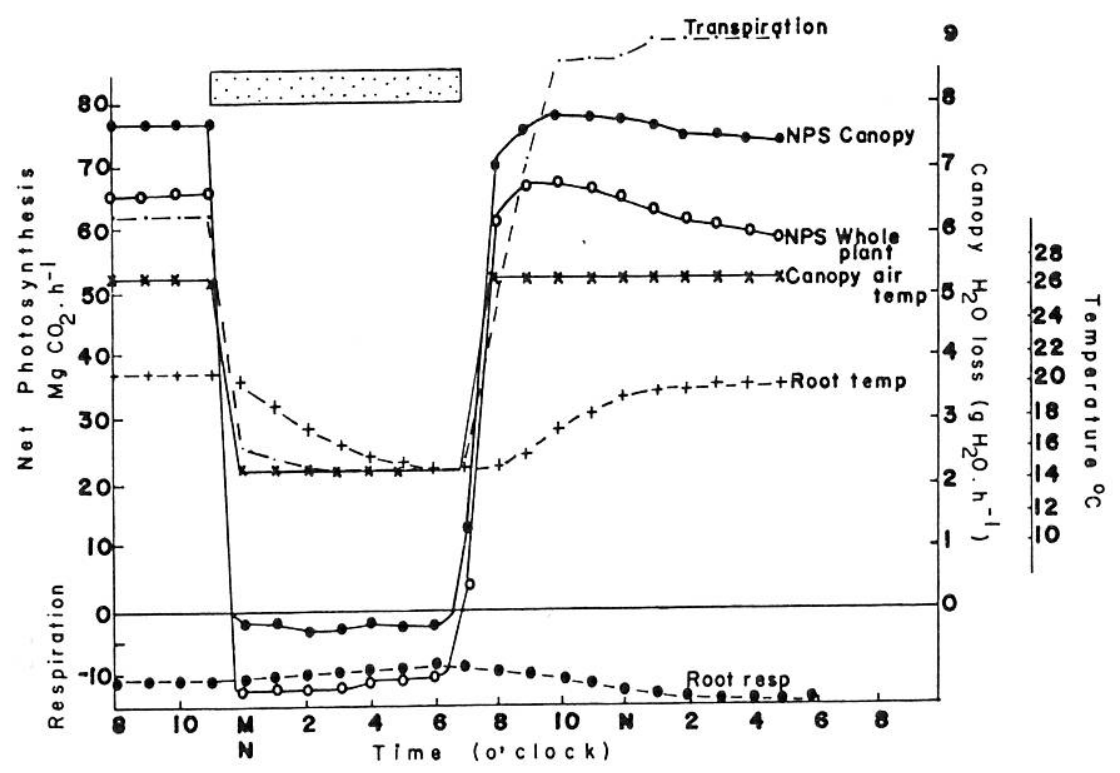


root respiration due to increased temperature hastened and enlarged the decrease that was apparent in the carbon gain of the whole plant but could not entirely account for the decreasing photosynthetic rates of the plant canopy.

When this feature was incorporated into the model the pattern of daily photosynthesis and respiration was accurately simulated (Fig. 7). Although decreasing the rate of net photosynthesis permitted a more accurate simulation by the model, the cause of the decline was not established. It is possible that either true photosynthesis decreased, or photorespiration increased. Another alternative is that the rate of wood respiration increased in response to an increased supply of carbohydrates produced during the early hours of photosynthesis. The daily $\mathrm{CO}_{2}$ gain by the population during the photoperiod, however, was underestimated about $25 \%$ by the computer. This was considered reasonably close to the actual $\mathrm{CO}_{2}$-exchange when one considers the cumulative effect of all

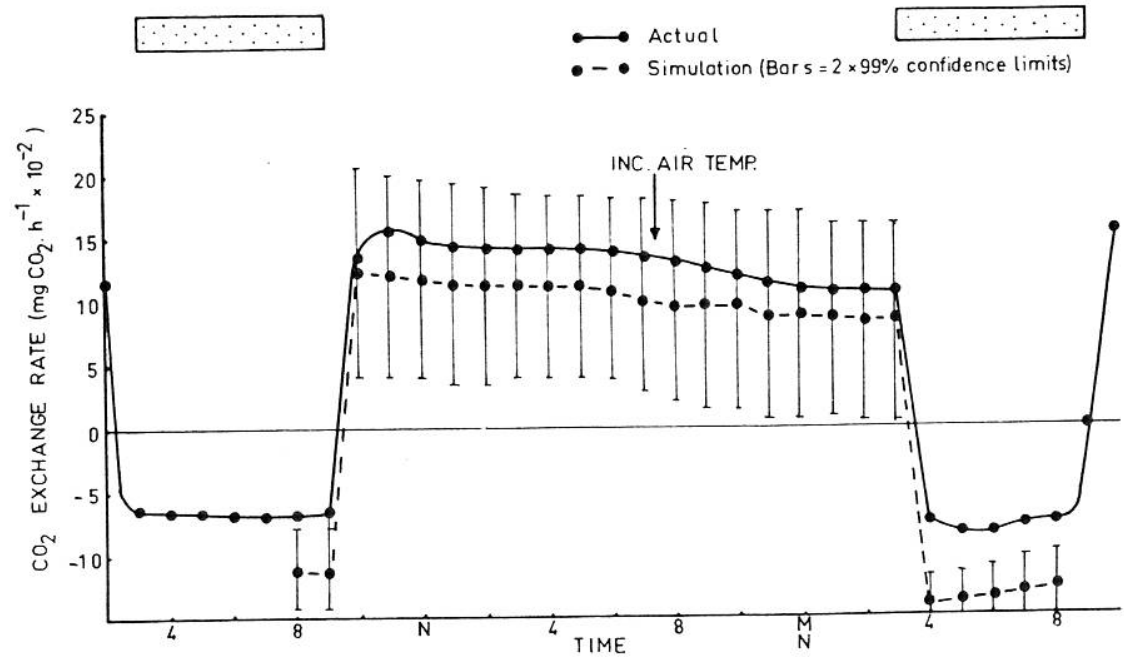

FIG. 7. Comparison of measured net assimilation rate for a population of aspen seedlings with a computer simulator. (Carbon gain distributed. Photosynthesis falling for last $11 \mathrm{~h}$ of the photoperiod.)
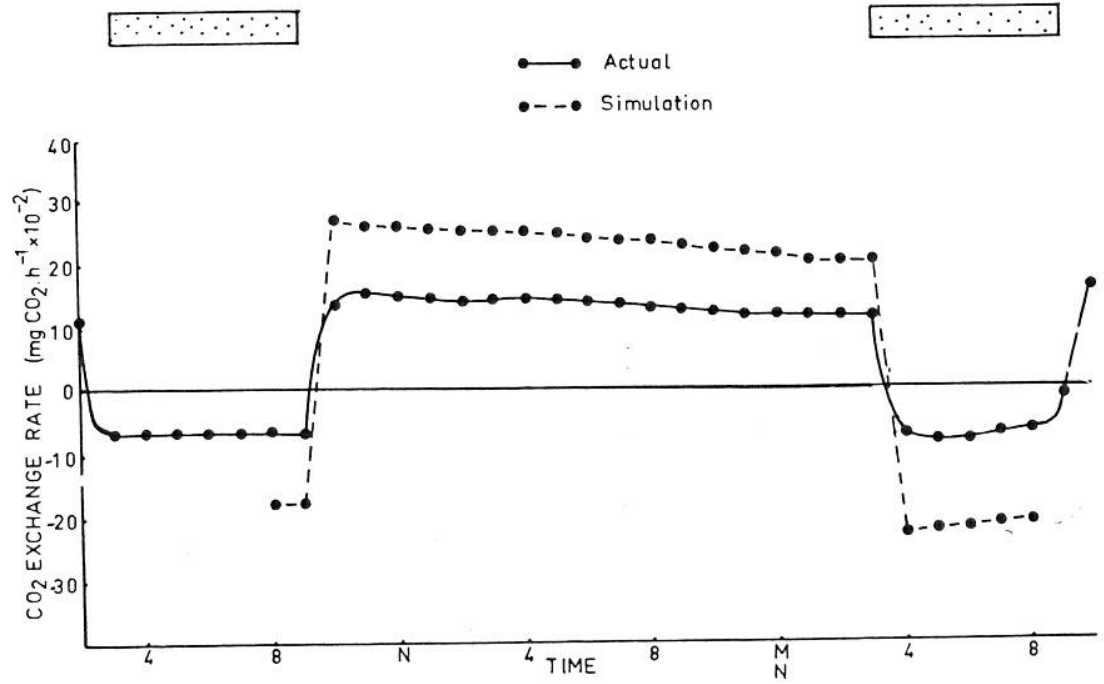

FIG. 8. Comparison of measured net assimilation rate for a population of aspen seedlings with a computer simulator. (Initial population weight estimated from a sample of five trees.) 
the standard errors of the parameters that were used in the calculations (see, for example, the $99 \%$ confidence limits). The respiration rates during the night period were about twice the actual rates and the $99 \%$ confidence limits did not include the actual rates. This suggests that the dark respiration rates used in the model were too large since the structure of the canopy was known accurately.

To show the erior introduced by using the five sample trees to estimate the structure of the whole population, the simulator was run using the total weights estimaled from the samples. The results (Fig. 8) show that the $\mathrm{CO}_{2}$-exchange during both the photo- and nycto-periods was grossly overestimated. In the 24 -h period included in the simulator using the actual plant weights (Fig. 7) the net carbon gain was $4.8 \mathrm{~g}$. The data from the estimated population weights showed a gain of $8.1 \mathrm{~g}$ carbon, a value $68 \%$ higher.

\section{Discussion}

Curry and Chen (1970) have pointed out that as agriculture becomes more intensive, the demand for various levels of control of the plant environment will increase. Dynamic models, which relate the response of the plant to the environment and which have capability for handling a large number of factors, "could provide the basis for the design and development of environmental controls for food production systems." The ultimate model would describe the plant environmental responses in terms of individual processes at the molecular level. For the time being, however, our knowledge of these basic processes is clearly insufficient and it is time to decide whether adequate empirical approximations can be made of the timeintegrated responses.

While the importance of plant responses to short-term micrometerological factors cannot be neglected it seems that there may be a place for both "descriptive" and "functional" models. The problems attendant with each are sufficiently complex to warrant their analysis separately, for it is possible that under certain circumstances the plant response may be sufficiently resilient to "take-up" differences in photosynthesis and respiration due to short-term microenvironmen- and the "descriptive" model adequate to achieve the aims. Since "descriptive" models are likely to prove more simple than "functional" models, their use should not be ignored simply on the basis that they do not answer the question "why?"

In the present paper we have attempted to ascertain the accuracy with which a descriptive model could predict the daily rate of $\mathrm{CO}_{2}$ exchange of a population of aspen trees. Even when the component parameters were gathered on the population and even with the structure of the population accurately known we are disappointed with the accuracy of the predictions. The daily carbon gain during the photoperiod was only predicted to within $25 \%$ of the actual, and predicted carbon loss during the night was about double the actual. Greater errors would have been obtained if the structure of the population had been based on the estimates from the sample trees and errors would certainly not have been lessened by integrating over a longer time period. It seems unlikely, at the present time, that the values of productivity predicted by models will be sufficiently accurate to have much practical use. The general similarity between the actual and the predicted $\mathrm{CO}_{2}$ exchange for the population suggest that the basic theory of the model may be reasonably correct. Before any further examination of the adequacy of the model is undertaken, however, it will be necessary to ensure that the coefficients $P$ and $q$ are accurately measured. This will only be possible with instruments which are accurately calibrated, have a proven record of repeatability, and are known to assess accurately $\mathrm{CO}_{2}$ exchange and dry-matter gain (Bate and Canvin $1971 a$ ). The errors shown in this simulation are most probably due to errors in the estimation of respiration coefficients. This arises because the gas analyzers only have a calibration accuracy of $\pm 3 \mathrm{ppm}$ at the $99 \%$ confidence limits. $\mathrm{CO}_{2}$ differentials of $10-15 \mathrm{ppm}$ were commonly experienced in these experiments and this could account for the error.

Figure 8 illustrated that the five sample trees were not an adequate sample of the whole population. It is probable, therefore, that the coefficients of respiration and photosynthesis for these sample trees did not provide an 
future experiments, hence the suitability of the sample as an estimate of the population should always be established.

\section{Acknowledgments}

This work was supported in part by the Canada Department of Fisheries and Forestry, the Canadian Committee for the International Biological Programme, and the National Research Council of Canada. The technical assistance of the programing staff at the Computer Center of Queen's University is greatly appreciated.

BAtE, G. C. 1970. Photosynthesis-productivity measurements on aspen trees in controlled environments. Ph.D. Thesis, Queen's University, Kingston, Ont.

Bate, G. C., A. D'Aoust, and D. T. Canvin. 1969. Calibration of infra-red $\mathrm{CO}_{2}$ gas analyzers. Plant Physiol. 44: 1122-1126.

BATE, G. C., and D. T. CANvin. 1971a. A gas-exchange system for measuring the productivity of plant populations in controlled environments. Can. J. Bot. 49: 601608.

1971b. The effect of some environmental factors on the growth of young aspen trees (Populus tremuloides Michx) in controlled environments. Can. J. Bot. 49: 1443-1453.

Curry, R. B., and L. H. Chen. 1970. Dynamic simulation of vegetative growth in a plant canopy. Proc. Summer Comput. Simulation Conf. pp. 737-745.

DEWIT, C. T. 1970. Dynamic concepts in biology. In Prediction and measurement of photosynthetic productivity. Edited by I. Setlik. Centre for Agricultural Publishing and Documentation, Wageningen, The Netherlands. pp. 17-23.
DeWIT, C. T., and R. Brouwer. 1968. Uber ein dynamisches Modell des vegetativen Wachstum von Pflanzenbestanden. Z. Angew. Bot. 42: 1-12.

DeWit, C. T., R. Brouwer, and F. W. T. PENNING de VRIES. 1970. The simulation of photosynthesis systems. In Prediction and measurement of photosynthetic productivity. Edited by I. Setlik. Centre for Agricultural Publishing and Documentation, Wageningen, The Netherlands. pp. 47-70.

Duncan, W. G., R. S. Loomis, W. A. Williams, and R. HANAN. 1967. A model for simulating photosynthesis in plant communities. Hilgardia, 38: 181-205.

LEDIG, F. T. 1969. A growth model for tree seedlings based on the rate of photosynthesis and the distribution of photosynthate. Photosynthetica, 3: 263-275.

LudWIG, L. J., and D. T. CANVIN. 1971. An open gasexchange system for the simultaneous measurement of the $\mathrm{CO}_{2}$ and ${ }^{14} \mathrm{CO}_{2}$ fluxes from leaves. Can. J. Bot. 49: 1299-1313.

Ludwig, L. J., T. Saeki, and L. T. Evans. 1965. Photosynthesis in artificial communities of cotton plants in relation to leaf area. I. Experiments with progressive defoliation of mature plants. Aust. J. Biol. Sci. 18: 1103-1117.

MCCREE, K. J. 1970. An equation for the rate of respiration of white clover plants grown under controlled conditions. In Prediction and measurement of photosynthetic productivity. Edited by I. Setlik. Centre for Agricultural Publishing and Documentation, Wageningen, The Netherlands. pp. 221-229.

Serlik, I. 1970. (Editor.) Prediction and measurement of photosynthetic productivity. Centre for Agricultural Publishing and Documentation, Wageningen, The Netherlands.

WAGGONER, P. E. 1969a. Predicting the effect upon net photosynthesis of changes in leaf metabolism and physics. Crop Sci. 9: 315-321. $1969 b$. Environmental manipulation for higher yields. In Physiological aspects of crop yields. Edited by J. D. Eastin, F. A. Haskins, C. Y. Sullivan, and C. H. M. VanBavel. Crop Science Society of America, Madison, Wisc. pp. 343-373. 